\title{
TASK-Like Conductances Are Present within Hippocampal CA1 Stratum Oriens Interneuron Subpopulations
}

\author{
Christine L. Torborg, ${ }^{1}$ Allison P. Berg, ${ }^{2}$ Brian W. Jeffries, ${ }^{1}$ Douglas A. Bayliss, ${ }^{2}$ and Chris J. McBain ${ }^{1}$ \\ ${ }^{1}$ Laboratory of Cellular and Synaptic Neurophysiology, National Institute of Child Health and Human Development, National Institutes of Health, Bethesda, \\ Maryland 20892, and ²Department of Pharmacology, University of Virginia, Charlottesville, Virginia 22908
}

\begin{abstract}
TASK-1 (KCNK3) and TASK-3 (KCNK9) are members of the two-pore domain potassium channel family and form either homomeric or heteromeric open-rectifier (leak) channels. Recent evidence suggests that these channels contribute to the resting potential and input resistance in several neuron types, including hippocampal CA1 pyramidal cells. However, the evidence for TWIK-related acid-sensitive potassium (TASK)-like conductances in inhibitory interneurons is less clear, and mRNA expression has suggested that TASK channels are expressed in only a subpopulation of interneurons. Here we use immunocytochemistry to demonstrate prominent TASK-3 protein expression in both parvalbumin-positive- and a subpopulation of glutamic acid decarboxylase (GAD)67-positive interneurons. In addition, a TASK-like current (modulated by both $\mathrm{pH}$ and bupivacaine) was detected in $30-50 \%$ of CA1 stratum oriens interneurons of various morphological classes. In most neurons, basic shifts in $\mathrm{pH}$ had a larger effect on the TASK-like current than acidic, suggesting that the current is mediated by TASK-1/TASK-3 heterodimers. These data suggest that TASK-like conductances are more prevalent in inhibitory interneurons than previously supposed.
\end{abstract}

Key words: potassium channels; interneurons; TASK; KCNK; hippocampus; inhibition

\section{Introduction}

Within the nervous system, local and global changes in $\mathrm{pH}$ occur under a variety of physiological and pathophysiological conditions, including synaptic transmission, high-frequency action potential firing, ischemia, and stroke (Kaila and Chesler, 1998; Katsura and Siesjo, 1998). These alterations in $\mathrm{pH}$ influence the function of nervous tissue, leading to increases or decreases in neuronal excitability (Balestrino and Somjen, 1988). Although numerous channels are sensitive to changes in $\mathrm{pH}$, Twik-related acid-sensitive potassium (TASK) channels are emerging as target $\mathrm{pH}$-sensitive ion channels that may be involved in $\mathrm{pH}$-dependent activity changes (Bayliss et al., 2003).

TASK channels are voltage independent, potassium selective channels belonging to the two-pore domain potassium channel family (Goldstein et al., 2001; Bayliss et al., 2003). TASK-1 (KCNK3) and TASK-3 (KCNK9) are the predominant TASK subunit types expressed in the brain (Talley et al., 2001) and exist as homodimers or as TASK-1/TASK-3 heterodimers. TASK-3 homodimers are more sensitive to acidification and less sensitive to alkalization than TASK-1 homodimers or TASK-1/TASK-3 heterodimers (Berg et al., 2004).

Within hippocampus, in situ hybridization has shown both

Received March 23, 2006; revised June 6, 2006; accepted June 6, 2006.

This work was supported by National Institute of Child Health and Human Development intramural funding to C.J.M., and National Institute of Neurological Disorders and Stroke Grants F31 NS50982 to A.P.B., and NS33583 to D.A.B.

Correspondence should be addressed to Christine L. Torborg, Laboratory on Cellular and Synaptic Neurophysiology, Building 35, Room 3C907, National Institute of Child Health and Human Development-Laboratory on Cellular and Synaptic Neurophysiology, Bethesda, MD 20892. E-mail: torborgc@mail.nih.gov.

DOI:10.1523/JNEUROSCI.1257-06.2006

Copyright $\odot 2006$ Society for Neuroscience $\quad$ 0270-6474/06/267362-06\$15.00/0
TASK-1 and TASK- 3 mRNA localized to the CA1 subfield (Talley et al., 2001). High levels of TASK-3 mRNA and lower levels of TASK-1 mRNA were observed in presumed stratum oriens (SO) inhibitory interneurons (Talley et al., 2001). However, in a separate study, single cell reverse transcription (RT)-PCR suggested that only $\sim 15 \%$ of CA1 SO interneurons with horizontally oriented dendrites contain TASK mRNA (Taverna et al., 2005). Furthermore, SO interneurons displayed "leakage" currents with weak acid sensitivity, consistent with expression of a TASK-like current (Taverna et al., 2005).

Because CA1 SO interneurons are a heterogeneous group (Somogyi and Klausberger, 2005), the possibility exists that TASK channels are expressed in other subpopulations, accounting for the disparity between in situ hybridization and single cell RTPCR data. It is well established that interneuron subpopulations often have distinct resting membrane potentials, input resistances, and membrane time constants, consistent with each having different complements of potassium leak channels.

Here we use immunohistochemistry to show that TASK-3 is expressed in most parvalbumin-positive interneurons as well as a subpopulation of somatostatin-containing interneurons. Furthermore, we demonstrate a TASK-like ( $\mathrm{pH}$ and bupivacaine sensitive) potassium current in a large number of horizontal CA1 $\mathrm{SO}$ interneurons. Based on the greater sensitivity of these neurons to alkalization than acidification, we suggest that channels are comprised of TASK-1/TASK-3 heterodimers.

\section{Materials and Methods}

All experiments were conducted in accordance with animal protocols approved by the National Institutes of Health.

Immunohistochemistry. Adult $(35-60 \mathrm{~d})$ or postnatal day 16 (P16) 
mice C57BL/6 mice were deeply anesthetized and transcardially perfused with PBS followed by $4 \%$ paraformaldehyde in $0.1 \mathrm{M}$ phosphate buffer (PFA). Brains were postfixed (2 h) in PFA and placed in $25 \%$ sucrose, $10 \%$ glycerol in $0.1 \mathrm{~m}$ phosphate buffer overnight and sectioned $(50 \mu \mathrm{m})$ with a freezing microtome.

Sections were permeabilized and blocked with $0.5 \%$ Triton X-100, $1 \%$ bovine serum albumin, and $10 \%$ goat serum in PBS $\left(1 \mathrm{~h}\right.$ at $\left.22^{\circ} \mathrm{C}\right)$. Primary antibody was added to carrier solution (with $0.1 \%$ Triton X-100, $1 \%$ bovine serum albumin, and $1 \%$ goat serum in PBS) with an additional $5 \%$ goat serum at the following concentrations: 1:1000 rabbit antiTASK-3, generated and characterized in house (Berg et al., 2004) or obtained from Santa Cruz Biotechnology (Santa Cruz, CA); 1:1000 mouse anti-parvalbumin (Sigma, St. Louis, MO); and 1:2000 mouse anti-GAD67 (Chemicon International, Temecula, CA). Sections were incubated for $48-96 \mathrm{~h}$ at $4^{\circ} \mathrm{C}$, washed with carrier solution, and incubated in secondary antibody [1:500 AlexaFluor 488 or 633 (Invitrogen, Carlsbad, CA); or 1:100 HRP-linked (Jackson ImmunoResearch, West Grove, PA) for TASK-3] in carrier solution $\left(1 \mathrm{~h}\right.$ at $\left.22^{\circ} \mathrm{C}\right)$. For adult TASK-3, a tyramide signal amplification system was used at 1:50 in amplification diluent (PerkinElmer, Boston, MA) for $10 \mathrm{~min}$. Slides were coverslipped with Mowiol and imaged.

Electrophysiology. Hippocampal slices from P14-P18 C57BL/6 mice were prepared as described previously (Pelkey et al., 2005). Slices were placed in a recording chamber and continuously perfused $(2-4 \mathrm{ml} / \mathrm{min})$ with artificial CSF containing the following (in $\mathrm{mm}$ ): $130 \mathrm{NaCl}, 3.5 \mathrm{KCl}$, $1.25 \mathrm{NaH}_{2} \mathrm{PO}_{4}, 25 \mathrm{NaHCO}_{3}, 2 \mathrm{CaCl}_{2}, 2 \mathrm{MgCl}_{2}$, and 10 glucose saturated with $95 \% \mathrm{O}_{2} / 5 \% \mathrm{CO}_{2}$, pH 7.4. CA1 SO interneurons were visually identified using a $40 \times$ objective and infrared differential interference contrast video microscopy (Axioskop; Zeiss, Oberkochen, Germany). Whole-cell patch-clamp recordings were performed at room temperature $\left(22^{\circ} \mathrm{C}\right.$ ) using a Multiclamp $700 \mathrm{~A}$ amplifier (Molecular Devices, Union City, CA). Recording electrodes (2.5-4 M $\Omega$ ) pulled from borosilicate glass (World Precision Instruments, Sarasota, FL) were filled with a solution containing the following (in mM): $130 \mathrm{KMeSO}_{4}, 10 \mathrm{HEPES}, 1$ EGTA, $0.1 \mathrm{CaCl}_{2}, 2 \mathrm{Na}_{2}$-ATP, $0.3 \mathrm{Na}_{2}$-GTP, $20 \mathrm{KCl}, 5 \mathrm{MgCl}_{2}, 0.05$ ZD7288 (to block the hyperpolarization-activated current, $I_{h}$; Tocris Bioscience, Ellisville, $\mathrm{MO}$ ), and $0.2 \%$ biocytin, $\mathrm{pH} 7.25$ with $\mathrm{KOH}$. In some experiments, the intracellular solution contained the following (in mM): 130 K-gluconate, 10 HEPES, 0.1 EGTA, $2 \mathrm{Na}_{2}$-ATP, $0.3 \mathrm{Na}_{2}$-GTP, $20 \mathrm{KCl}, 5 \mathrm{MgCl}_{2}, 0.05 \mathrm{ZD} 7288$, and $0.2 \%$ biocytin, pH 7.25 with $\mathrm{KOH}$. For most experiments, cells were voltage clamped at $-60 \mathrm{mV}$, and -5 $\mathrm{mV}$ steps were delivered every $15 \mathrm{~s}$ to monitor input and series resistances. The current-voltage relationship was determined either by delivering $10 \mathrm{mV}$ steps from -120 to -60 or by a slow voltage ramp (10 $\mathrm{mV} / \mathrm{s}$ ). Data acquisition (filtered at $3 \mathrm{kHz}$ and digitized at $10 \mathrm{kHz}$ ) was performed with pClamp 9.2 software (Molecular Devices). In all experiments, $1 \mu \mathrm{M}$ tetrodotoxin (Sigma) was added to the bath solution, and in most experiments, $25 \mu \mathrm{M}$ DNQX (Sigma); $100 \mu \mathrm{M}$ DL-APV (Tocris Bioscience); $5 \mu \mathrm{M}$ SR95531 (Tocris Bioscience); or $100 \mu \mathrm{M}$ picrotoxin (Tocris Bioscience), and $250 \mathrm{~nm}$ CGP55845 (Tocris Bioscience) was included to block AMPA-, NMDA-, $\mathrm{GABA}_{\mathrm{A}^{-}}$, and $\mathrm{GABA}_{\mathrm{B}}$-receptor-mediated synaptic transmission, respectively.

Analysis of electrophysiological recordings. Data were analyzed using IgorPro 5.0 (Wavemetrics, Lake Oswego, OR). In voltage clamp, cell input resistance was determined by delivering a $50 \mathrm{~ms},-5 \mathrm{mV}$ step and calculated from the reciprocal of the average current amplitude of the last $10 \mathrm{~ms}$ divided by the voltage step. $I-V$ curves were fit with the following Goldman-Hodgkin-Katz (GHK) current equation (Hille, 2001):

$$
I_{s}=P_{s} z_{s} \frac{E F^{2}}{R T} \frac{[S]_{i}-[S]_{o} \exp \left(-z_{s} F E / R T\right)}{1-\exp \left(-z_{s} F E / R T\right)},
$$

where $P_{S}$ is the permeability, $[S]_{i}$ and $[S]_{o}$ are the intracellular and extracellular concentrations of potassium, $z_{s}$ is the valence, $F$ is Faraday's constant, $R$ is the gas constant, $E$ is the voltage, and $T$ is the absolute temperature. The $\mathrm{pH}$-sensitive current was obtained by subtracting the control ( $\mathrm{pH} 7.4)$ current from the current measured in either acidic $(\mathrm{pH}$ 6.4) or basic ( $\mathrm{pH} 8.4$ ) solution. Data were corrected for the measured junction potentials of $-6.5 \mathrm{mV}$ (potassium gluconate internal solution) or $-5.5 \mathrm{mV}$ (potassium methyl sulfate internal solution). Changing the $\mathrm{pH}$ did not alter the junction potential. Data are presented as mean \pm SEM.

\section{Results}

TASK-3 is primarily expressed in parvalbumin-positive cells Previous studies using in situ hybridization techniques suggested that TASK-3 mRNA is localized to interneurons in CA1 SO (Talley et al., 2001). Using immunohistochemistry, we labeled coronal sections of mouse hippocampus with a TASK-3 antibody. TASK-3 expression was observed throughout the adult hippocampus (Fig. $1 A$ ) in a pattern consistent with that shown by in situ hybridization (Talley et al., 2001). TASK-3-immunoreactive interneurons were scattered throughout CA1 SO, primarily in cells with large vertically oriented primary dendrites (Fig. $1 B$ ) but also in cells with horizontally oriented primary dendrites (Fig. 1C). A similar pattern of TASK-3 immunoreactivity was also observed in juvenile (P16) mice (Fig. 1C). Double labeling with GAD67, a marker for GABAergic interneurons, revealed that $83 \pm 3 \%$ of TASK-3-immunoreactive CA1 SO neurons were also GAD67 positive (Fig. $1 D, G$ ), confirming that TASK-3-positive neurons in the stratum oriens are indeed GABAergic interneurons. However, only $49 \pm 6 \%$ of GAD67-positive neurons contained TASK-3 (Fig. $1 D, H$ ), suggesting that not all GABAergic interneurons contain TASK-3.

GABAergic interneurons can be divided into several subpopulations based on the markers that they express. Double labeling with antibodies to parvalbumin and TASK-3 revealed that $95 \pm 3 \%$ of TASK-3-positive cells were parvalbumin positive (Fig. $1 E, G$ ) and that $97 \pm 4 \%$ of parvalbumin-immunoreactive cells were also TASK-3 immunoreactive (Fig. $1 H$ ). Similarly, in juvenile (P16) mice, $93 \pm 1 \%$ of parvalbumin-immunoreactive cells also expressed TASK-3. In mice expressing EGFP under the GAD67 promoter (GAD67-EGFP) a subset of GAD67-positive interneurons express EGFP (Oliva et al., 2000). These interneurons are somatostatin positive and project their axons to lacunosum moleculare. In tissue obtained from these mice, $66 \pm 5 \%$ of GAD67-EGFP-positive interneurons exhibited TASK-3 immunoreactivity (Fig. $1 F, H$ ) and represented $22 \pm 2 \%$ of TASK-3positive neurons (Fig. 1G). The combined total of TASK-3positive cells expressing parvalbumin or EGFP is $>100 \%$, suggesting overlap between these two populations, consistent with previous reports (Somogyi and Klausberger, 2005). Attempts to determine the TASK-3 content of other neurochemically defined populations of interneurons was equivocal and suggests that TASK-3 is largely expressed in parvalbumincontaining, and a subpopulation of somatostatin-containing interneurons. Importantly, these data indicate that TASK-3 protein is expressed in a greater number of CA1 interneurons than suggested previously (Taverna et al. 2005).

\section{CA1 SO interneurons contain a TASK-like current}

Although no specific inhibitors of TASK channels exist, the conductance of recombinant TASK channels is decreased by extracellular acidification and increased by alkalization (Bayliss et al., 2003). To determine the prevalence of TASK-like conductances in CA1 SO inhibitory interneurons, we made whole-cell patchclamp recordings from visually identified and anatomically confirmed interneurons. We tested 27 cells for sensitivity to both basic and acidic changes in $\mathrm{pH}$, of which nine displayed changes in holding current, input resistance, and reversal potential that were consistent with a TASK-like current. In these nine cells, bath alkalization caused a positive shift in the amount of current re- 

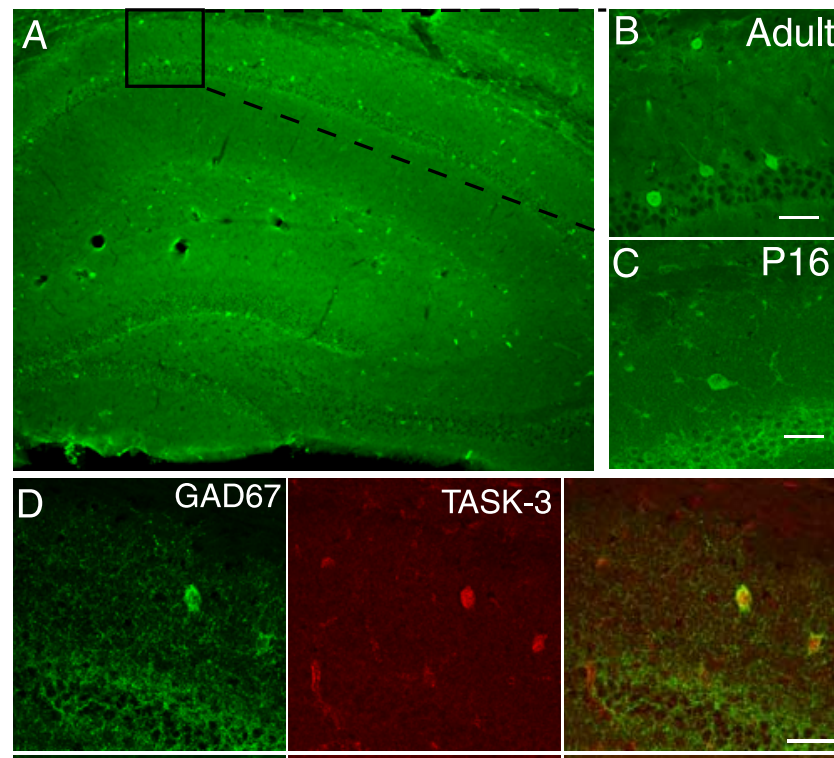

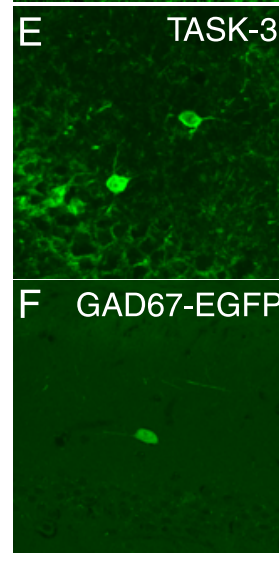

G



$\mathrm{H}$

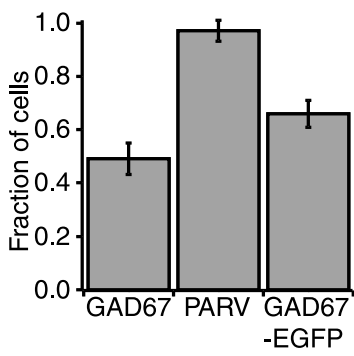

Figure 1. TASK-3 is expressed in CA1 S0 interneurons. A, Low-power (10X) image of a coronal section of adult mouse hippocampus immunolabeled with TASK-3 antibody (green). TASK-3 immunoreactivity is seen throughout the hippocampus. $\boldsymbol{B}$, High-power $(40 \times)$ image of CA1 S0. C, High-power (40X) image of a TASK-3-positive interneuron from a juvenile (P16) mouse. D, TASK-3 immunoreactivity (red) colocalizes with GAD67 immunoreactivity (green), a marker for GABAergic interneurons. $\boldsymbol{E}$, TASK-3 (green) is found in parvalbumin (PARV) (red) -positive interneurons. $\boldsymbol{F}$, In mice expressing EGFP in a subset of GAD67-positive interneurons, TASK-3 immunoreactivity (red) is present in some neurons expressing EGFP (green). G, Summary of the fraction of TASK-3-positive cells in CA1 S0 that also expressed GAD67, parvalbumin, or EGFP under the GAD67 promoter (GAD67-EGFP). $\boldsymbol{H}$, Summary of the fraction of cells expressing each marker that also express TASK-3. This fraction was calculated by dividing the number of colocalized cells by the total number that express each marker. For GAD67-EGFP, $n=13$ sections, four animals; PARV and GAD67, $n=6$ sections, three animals. Error bars equal SEM. Scale bars, $50 \mu \mathrm{m}$.

quired to hold the cell at $-60 \mathrm{mV}(\mathrm{pH} 7.4,-35 \pm 11 \mathrm{pA} ; \mathrm{pH} 8.4$, $22 \pm 10 \mathrm{pA} ; n=9 ; p<0.001$ ), concomitant with a decrease in the input resistance of the cell $(\mathrm{pH} 7.4,447 \pm 69 \mathrm{M} \Omega ; \mathrm{pH}$ 8.4, $196 \pm$ $27 \mathrm{M} \Omega ; n=9 ; p<0.001$ ) (Fig. $2 A-D$ ), both of which are consis- tent with an increase in a leakage potassium conductance. Bath acidification resulted in a small, but not significant $(p>0.05)$ increase in the amount of negative holding current $(\mathrm{pH} 7.4$, $-35 \pm 11 ; \mathrm{pH} 6.4,-46 \pm 12 \mathrm{pA} ; n=9$ ) (Fig. $2 A i, C$ ), which was associated with a small, but not significant $(p>0.05)$, increase in the input resistance of the cell $(\mathrm{pH} 7.4,447 \pm 69 \mathrm{M} \Omega$; $\mathrm{pH} 6.4$ $478 \pm 68 \mathrm{M} \Omega ; n=9$ ) (Fig. 2Ai,D). Notably, in one of those nine cells, bath acidification led to a large change $(-90 \mathrm{pA})$ in the holding current as well as a 26\% (pH 7.4, $78 \mathrm{M} \Omega ; \mathrm{pH} 6.4,98 \mathrm{M} \Omega)$ increase in the input resistance (Fig. $2 B$ ).

Although little change in holding current was observed at holding potentials close to rest, a larger change was apparent at more negative potentials in these same nine cells. At a holding potential of $-115 \mathrm{mV}$, a $24 \pm 6 \mathrm{pA}$ outward current was detected in response to $1 \mathrm{pH}$ unit of acidification, whereas a $-65 \pm 7 \mathrm{pA}$ inward current was detected in response to $1 \mathrm{pH}$ unit of alkalization (current values are relative to current measured at $\mathrm{pH} 7.4$ ) (Fig. 2E). Because bath alkalization resulted in a larger TASK-like current at resting potentials, subsequent analysis was performed only on the currents evoked by high $\mathrm{pH}$.

To determine whether the current activated by alkalization was both time and voltage independent, hallmark properties of TASK-like conductances, we next measured the current-voltage $(I-V)$ relationship of the $\mathrm{pH}$-sensitive response in CA1 interneurons using either voltage steps or ramps delivered from -125 $\mathrm{mV}$. To obtain the $\mathrm{pH}$-sensitive current, the control ( $\mathrm{pH}$ 7.4) current was subtracted from the current in basic $(\mathrm{pH}$ 8.4) solution (Fig. $2 A i i, B i i, F$ ). Voltage and time independence was tested by fitting the isolated $\mathrm{pH}$-sensitive current to the modified GHK equation. Figure 2 shows that the $I-V$ relationship of the basesensitive current is well described by the GHK equation with a measured reversal potential close to the calculated $E_{K}$ (measured reversal, $-86.5 \pm 2.4 \mathrm{mV} ; n=9$; calculated $E_{K},-95.5 \mathrm{mV}$ ). However, to verify that this isolated current was indeed potassium selective, in a separate series of experiments, the baseinduced current was measured in an increased extracellular potassium concentration $(8.5 \mathrm{~mm})$. If the activated current is $\mathrm{K}$ selective, $E_{K}$ should shift by a calculated $+22.5 \mathrm{mV}$. Indeed, in elevated potassium solution, 10 of 19 cells responded to alkalization with a current whose $I-V$ relationship was again well fit by the GHK equation and reversed at $-63.4 \pm 0.7 \mathrm{mV}(n=10)$, representing a shift of $23.1 \mathrm{mV}$ (Fig. $2 F$ ). These data indicate that the alkalization-activated current is a K-selective openly rectifying current.

To verify that these changes in holding current during voltageclamp recordings manifested as changes in membrane potential, we next performed whole-cell current-clamp recordings in a separate set of experiments. Under control conditions, the average resting potential of CA1 SO interneurons was $-54.2 \pm 1.1 \mathrm{mV}$ $(n=16)$. After bath alkalization, 10 of 16 neurons hyperpolarized, with an average change in resting potential of $-12.8 \pm 2.3$ $\mathrm{mV}(p<0.001)$ (Fig. 2G,H). The resting potential of the subpopulation of neurons that hyperpolarized in response to alkalization was $-55.9 \pm 1.4 \mathrm{mV}(n=10)$, which was significantly more negative than that of neurons that did not respond $(-51.5 \pm 0.9 \mathrm{mV} ; n=6 ; p<0.05)$. Furthermore, the average resting potential of nonresponders was unchanged after $5 \mathrm{~min}$ in alkaline solution $(-50.3 \pm 0.7 \mathrm{mV} ; p>0.05)$.

Another hallmark property of TASK conductances is their block by local anesthetics such as bupivacaine (Bayliss et al., 2003). In another set of experiments, we first applied basic solution to increase the TASK-like current, and then applied the local anesthetic bupivacaine (20 $\mu$; Sigma). In 9 of 22 CA1 SO inter- 

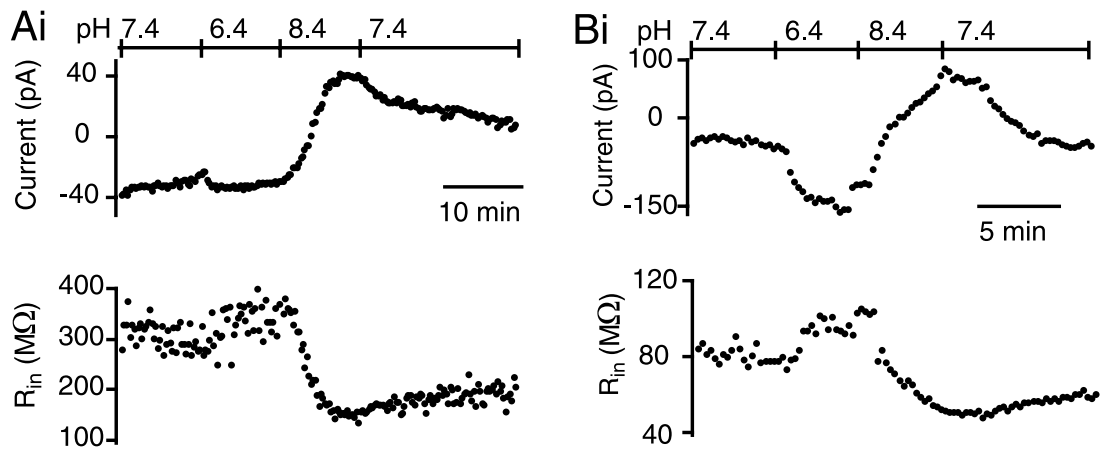

Aii
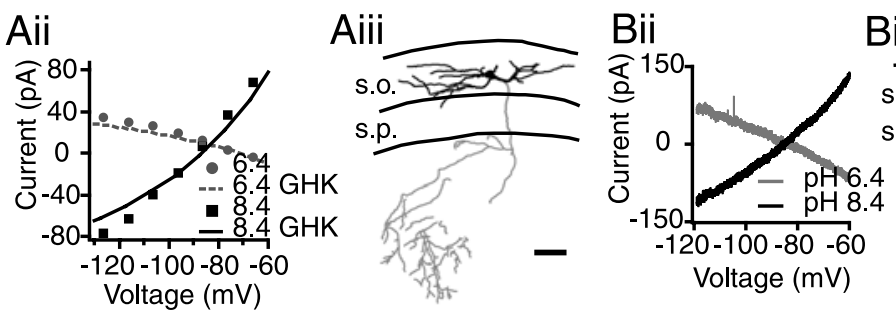

Biii
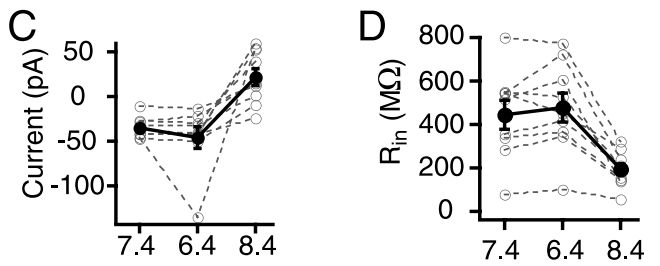

E

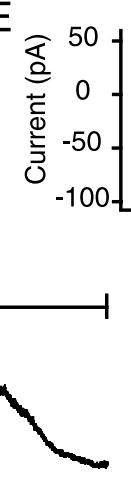

$2 \mathrm{~min}$

$$
\begin{aligned}
& G \\
& 3.5 \\
& 8.5
\end{aligned}
$$



Figure 2. A pH-sensitive potassium current is present in some CA1 SO interneurons. $\boldsymbol{A}$, Whole-cell voltage-clamp recording of a pH-sensitive interneuron. $\mathbf{A i}$, The holding current became slightly more negative after bath acidification and more positive after alkalization. The input resistance decreased after alkalization, indicating that a pH-sensitive conductance was increased. Aii, Current-voltage relationship in response to voltage steps from -125 to $-65 \mathrm{mV}$ at each $\mathrm{pH}$. The $\mathrm{pH}$-sensitive current was obtained by subtracting the control current from current obtained in high or low $\mathrm{pH}$. The GHK fit for each curve is represented by the dotted (pH 6.4) and solid (pH 8.4) lines. Aiii, Representative example neurolucida drawing of a pH-sensitive neuron. Scale bar, $100 \mu \mathrm{m} . \boldsymbol{B}$, Whole-cell voltage-clamp recording of a $\mathrm{pH}$-sensitive interneuron that responded to acidification. $\mathbf{B i}$, The holding current became more negative after bath acidification and more positive after alkalization (top). The input resistance increased with acidification and decreased with alkalization (bottom). Bii, Current-voltage relationship of the pH-sensitive current. Biii, Neurolucida drawing of this pH-sensitive neuron. S.0., Stratum oriens; s.p., stratum pyramidale. Scale bar, $100 \mu \mathrm{m}$. C, Summary of the effect of pH on holding current in all pH-sensitive cells. $\boldsymbol{C}, \boldsymbol{D}, \boldsymbol{E}, \boldsymbol{H}$, Open gray circles and dotted lines represent individual cells, and filled black circles and solid lines represent the mean data. $\boldsymbol{D}$, Summary of the effect of $\mathrm{pH}$ on input resistance. $\boldsymbol{E}$, Comparison of the magnitude of the current activated in acidic and basic solutions, measured at a holding potential of $-115 \mathrm{mV}$. $\boldsymbol{F}$, Summary of the current-voltage relationship of interneurons in $3.5 \mathrm{~mm}$

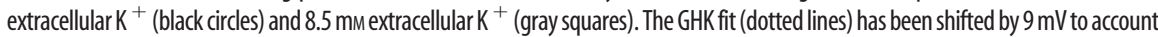
for the difference between calculated and observed reversal potentials. Only cells that exhibited a $\mathrm{pH}$-sensitive current that reversed within the range tested and that had a decrease in input resistance during bath alkalization were included in this and subsequent analyses $(n=$ 9). $\boldsymbol{G}$, Example of a whole-cell current-clamp recording of a neuron that hyperpolarized in base. $\boldsymbol{H}$, Summary of the change in resting potential during alkalization. Error bars equal SEM.

neurons, alkalization resulted in a more positive holding current $(88 \pm 21 \mathrm{pA})$, decrease in input resistance $(\mathrm{pH} 7.4,323 \pm 42 \mathrm{M} \Omega$; $\mathrm{pH} 8.4,129 \pm 36 \mathrm{M} \Omega$ ), and a voltage-independent current that reversed near $E_{K}(-88 \pm 1.1 \mathrm{mV})$, consistent with those cells containing a TASK-like current. In these nine interneurons, bupivacaine almost completely reversed the alkalization-activated current (mean decrease in holding current, $-82 \pm 22 \mathrm{pA}$ ), concomitant with an increase in the input resistance ( $\mathrm{pH} 8.4,129 \pm$ $36 \mathrm{M} \Omega$; pH 8.4 and bupivacaine, $256 \pm 31 \mathrm{M} \Omega$ ) (Fig. 3).

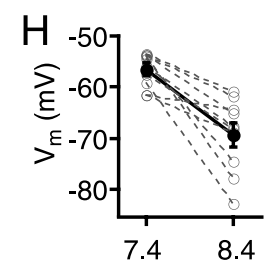

To determine whether this TASK-like current was found in morphologically distinct interneuron classes, cells were filled with biocytin during whole-cell recordings and anatomical reconstruction performed post hoc. We recovered the morphology of 26 cells that contained a TASK-like current. Of these 26 cells, 25 had horizontally oriented dendrites and cell bodies in CA1 SO but varied in their axonal morphologies. The large percentage of horizontal cells is likely the result of a selection bias while patching cells. In 16 cells, the axon crossed stratum (str.) pyramidale and projected to str. lacunosum moleculare, where they branched extensively, consistent with them being oriens-lacunosum moleculare (OLM) cells (Fig. 2 Aiii). Three cells had axons confined to str. pyramidale or proximal str. radiatum (basket/chandelier cells), and one was a back-projecting cell with axon ramifying both in CA1 and CA 3 str. radiatum (Fig. $3 C)$. The remaining five cells had insufficient axon for positive identification. Finally, one cell had a cell body in CA1 SO but had vertically oriented dendrites, consistent with a basket cell morphology; however, the axon for this cell was not recovered (Fig. 2 Biii). Of interest, this was the one cell with the largest response to acidification (Fig. $2 \mathrm{~B}$ ). Together these anatomical features are consistent with the immunohistochemical detection of TASK-3 in both somatostatin- and parvalbumin-containing interneurons.

\section{Many CA1 SO interneurons do not exhibit a TASK-like current}

Although we observed many cells with TASK-like currents, just over half of the interneurons tested under voltage-clamp conditions (39 of 67) did not display a TASK-like current, i.e., they did not respond to $\mathrm{pH}$ changes, did not display the expected change in input resistance, and the $\mathrm{pH}$-sensitive current was not described by the GHK relationship. Eighteen neurons fit all three of these criteria. Figure $4 A-C$ shows one example of a neuron that clearly did not contain TASK-like current. Both the holding current and input resistance were resistant to both alkalization and bupivacaine (Fig. 4A). Furthermore, the subtracted $I-V$ showed no current activated in either condition (Fig. $4 B)$. The morphologies of 10 interneurons that clearly did not display TASK-like current were recovered, and all of them had horizontal dendrites and cell bodies in CA1 SO. Five of these were identified as O-LM cells, and two were identified as basket/chandelier cells (Fig. 3C). The remaining neurons consisted of one bistratified cell with axon ramifying in SO and str. radiatum and two cells with insufficient axon for positive identification.

Twenty-one neurons partially fit the criteria for containing a TASK-like current, fitting at least one of the criteria but not all 
three. Figure $4 D-F$ illustrates an example of a neuron in which the input resistance increased during acidification and decreased input resistance with alkalization, which were associated with changes in holding current (Fig. 4D). However, the isolated $\mathrm{pH}$-sensitive $I-V$ relationship was not adequately described by the GHK equation (Fig. $4 E$ ). All 13 recovered neurons had horizontally oriented dendrites. Of these, nine were identified as O-LM cells, and four had insufficient axon for additional characterization. Because of their ambiguity, these cells were omitted from the overall TASK-positive dataset.

For the 16 neurons tested in current clamp, six neurons did not hyperpolarize after addition of basic solution; rather, they had an average change in resting potential of $1.2 \pm 0.7 \mathrm{mV}$, which was not significant. Of the three recovered neurons, two were O-LM neurons, and one was a horizontal neuron with insufficient axon for additional characterization.

\section{Discussion}

GABAergic interneurons vary widely in both their morphological and functional properties. The major source of functional heterogeneity arises from the distinct ion channel complements expressed in particular cell types (McBain and Fisahn, 2001). In the present study, we observed TASK-3 immunoreactivity in $\sim 50 \%$ of GAD67positive interneurons. Similarly, TASKlike conductances were observed in just under half of all interneurons tested. TASK-3 protein was expressed primarily in parvalbumincontaining and a subset of GAD-EGFP (somatostatin)containing SO neurons, which are mainly basket/chandelier and O-LM neurons, respectively. Consistent with this observation, morphologically identified CA1 SO neurons exhibiting TASKlike current were predominantly O-LM and basket/chandelier neurons.

TASK channel expression in SO interneurons has been previously investigated by Taverna et al. (2005), who concluded that TASK-like currents are not consistently detectable in horizontal CA1 SO interneurons, and only $\sim 15 \%$ of CA1 SO interneurons express TASK-3 mRNA. However, in the present study, $\sim 50 \%$ of morphologically identified horizontal interneurons displayed a TASK-like current. Furthermore, TASK-3 immunoreactivity was present in 66\% of GAD67-GFP CA1 SO interneurons, of which the O-LM represents a subpopulation. This apparent discrepancy between our results and those of Taverna et al. (2005) likely results from the different methods used to detect the TASK-like conductance. First, Taverna et al. (2005), used single-cell PCR to determine TASK expression, which may have underestimated the number of cells expressing TASK mRNA. Consistent with this hypothesis, in the Taverna et al. (2005) study, electrophysiological data suggested that all pyramidal cells expressed TASK-like current, whereas mRNA was only detected in $\sim 50 \%$ of pyramidal cells. Second, in our recordings the acid-sensitive current was small enough such that without subsequent detection of the base- sensitive current, it is likely that we also would have identified these cells as pH insensitive. Because Taverna et al. (2005) relied on only acid sensitivity, the small $(\sim 2 \mathrm{mV})$ depolarization that they observed in acidic solutions did not conclusively identify them as $\mathrm{pH}$ sensitive.

TASK-like current in CA1 SO interneurons was only weakly sensitive to acid $\mathrm{pH}$, consistent with a previous report that acidification results in only a small $(\sim 2 \mathrm{mV})$ depolarization of the resting potential in horizontal interneurons (Taverna et al., 2005). In contrast, the TASK-like current was much more sensitive to alkalization, which resulted in a more than twofold greater change in current than acidification (Fig. 2). This $\mathrm{pH}$-sensitivity profile provides a tentative indication of the molecular identity of the underlying TASK channels. Although all combinations of TASK-1 and TASK-3 dimers have some sensitivity to acidification, TASK-1 homodimers and TASK-1/TASK-3 heterodimers have large increases in conductance during bath alkalization $(\mathrm{Cz}-$ irjak and Enyedi, 2002; Berg et al., 2004; Kang et al., 2004), whereas TASK-3 homodimers exhibit only a small increase in conductance during bath alkalization (Kim et al., 2000; Berg et al., 2004). In our recordings the current increase during alkalization is larger than the decrease during acidification, suggesting that TASK channels in SO interneurons may comprise either TASK-1/TASK-3 heterodimers or TASK-1 homodimers. Consistent with this hypothesis, low levels of TASK-1 mRNA have been observed in CA1 by both single-cell PCR (Taverna et al., 2005) 


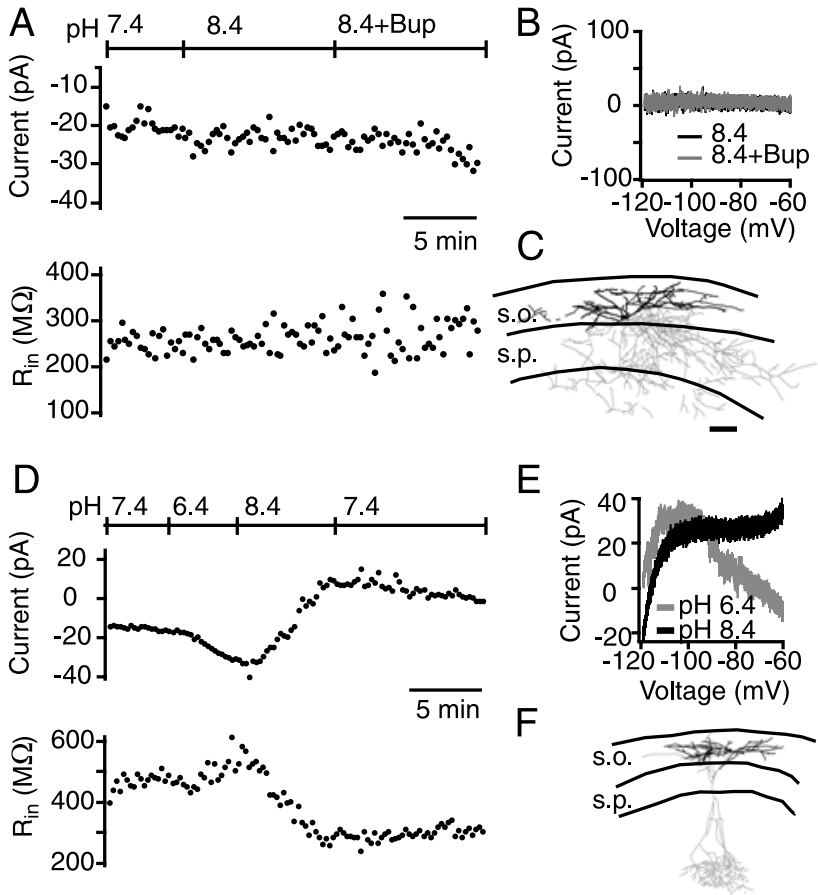

Figure 4. Many interneurons did not exhibit TASK-like currents. $\boldsymbol{A}$, Whole-cell voltageclamp recording of a $\mathrm{pH}$ - and bupivacaine-insensitive neuron. Neither the holding current (top) nor input resistance (bottom) changed in high pH or high pH and $20 \mu \mathrm{m}$ bupivacaine. $\boldsymbol{B}$, Subtracted current-voltage relationship for the same cell as in $\boldsymbol{A}$. Bup, Bupivacaine. $\boldsymbol{C}$, Neurolucida drawing of the $\mathrm{pH}$ and bupivacaine-insensitive cell in $\boldsymbol{A}$. s.0., Stratum oriens; s.p., stratum pyramidale. $\boldsymbol{D}$, Whole-cell voltage-clamp recording of an anomalous $\mathrm{pH}$-sensitive neuron. Both the holding current (top) and input resistance (bottom) changed in both low and high pH. $\boldsymbol{E}$, Subtracted $/-V$ plot for the same cell as in $\boldsymbol{D}$. The current-voltage relationship deviated from the expected GHK relationship and showed a large degree of rectification. $\boldsymbol{F}$, Example neurolucida drawing of a $\mathrm{pH}$-sensitive cell with an ambiguous $\mathrm{I}-\mathrm{V}$.

and in situ hybridization (Talley et al., 2001). Moreover, Taverna et al. (2005) reported a hyperpolarization of interneurons in response to bath application of the volatile anesthetic isoflurane, which increases current through TASK-1/TASK-3 heterodimers but not TASK-1 homodimers (Berg et al., 2004).

Although TASK channels are present in horizontal CA1 SO interneurons, they make a minor contribution to the resting potential at normal $\mathrm{pH}(\sim 7.4)$. The resting membrane potential of CA1 SO interneurons with a TASK-like conductance was only 4 $\mathrm{mV}$ more hyperpolarized than those that did not contain TASK. Additionally, acidification had only a small effect on the potassium current, consistent with a small role for TASK at normal $\mathrm{pH}$. However, alkalization resulted in a large increase in the potassium leak current and a significant hyperpolarization of the membrane potential, suggesting that in interneurons, their function is relevant at $\mathrm{pH}$ ranges slightly above normal. Within the
CA1 hippocampus, periods of high action-potential frequency transiently elevates extracellular pH (Kaila and Chesler, 1998). This transient $\mathrm{pH}$ elevation will increase the interneuron TASK current, decreasing excitability and potentially minimizing the role played by these interneurons during periods of excessive activity. The two subpopulations that we have identified as containing TASK, namely basket and O-LM cells, are involved in feedforward and feedback inhibition, respectively. Thus, TASKdependent alterations in excitability may serve to regulate both feedforward and feedback inhibition.

\section{References}

Balestrino M, Somjen GG (1988) Concentration of carbon dioxide, interstitial $\mathrm{pH}$ and synaptic transmission in hippocampal formation of the rat. J Physiol (Lond) 396:247-266.

Bayliss DA, Sirois JE, Talley EM (2003) The TASK family: two-pore domain background $\mathrm{K}+$ channels. Mol Interv 3:205-219.

Berg AP, Talley EM, Manger JP, Bayliss DA (2004) Motoneurons express heteromeric TWIK-related acid-sensitive $\mathrm{K}^{+}$(TASK) channels containing TASK-1 (KCNK3) and TASK-3 (KCNK9) subunits. J Neurosci 24:6693-6702.

Czirjak G, Enyedi P (2002) Formation of functional heterodimers between the TASK-1 and TASK-3 two-pore domain potassium channel subunits. J Biol Chem 277:5426-5432.

Goldstein SA, Bockenhauer D, O'Kelly I, Zilberberg N (2001) Potassium leak channels and the KCNK family of two-P-domain subunits. Nat Rev Neurosci 2:175-184.

Hille B (2001) Ion channels of excitable membranes. Sunderland, MA: Sinauer.

Kaila K, Chesler M (1998) Activity-evoked changes in extracellular pH. In: pH and brain function (Kaila K, Ransom B, eds), pp 309-337. New York: Wiley-Liss.

Kang D, Han J, Talley EM, Bayliss DA, Kim D (2004) Functional expression of TASK-1/TASK-3 heteromers in cerebellar granule cells. J Physiol (Lond) 554:64-77.

Katsura K, Siesjo BK (1998) Acid-base metabolism in ischemia. In: pH and brain function (Kaila K, Ransom B, eds), pp 563-582. New York: WileyLiss.

Kim Y, Bang H, Kim D (2000) TASK-3, a new member of the tandem pore $\mathrm{K}(+)$ channel family. J Biol Chem 275:9340-9347.

McBain CJ, Fisahn A (2001) Interneurons unbound. Nat Rev Neurosci 2:11-23.

Oliva Jr AA, Jiang M, Lam T, Smith KL, Swann JW (2000) Novel hippocampal interneuronal subtypes identified using transgenic mice that express green fluorescent protein in GABAergic interneurons. J Neurosci 20:3354-3368

Pelkey KA, Lavezzari G, Racca C, Roche KW, McBain CJ (2005) mGluR7 is a metaplastic switch controlling bidirectional plasticity of feedforward inhibition. Neuron 46:89-102.

Somogyi P, Klausberger T (2005) Defined types of cortical interneurone structure space and spike timing in the hippocampus. J Physiol (Lond) $562: 9-26$

Talley EM, Solorzano G, Lei Q, Kim D, Bayliss DA (2001) CNS distribution of members of the two-pore-domain (KCNK) potassium channel family. J Neurosci 21:7491-7505.

Taverna S, Tkatch T, Metz AE, Martina M (2005) Differential expression of TASK channels between horizontal interneurons and pyramidal cells of rat hippocampus. J Neurosci 25:9162-9170. 